\title{
Chlamydia Pneumoniae and Acute Aortic Syndrome: A Call for a Multi-Institutional Study
}

\section{Clamidia Pneumoniae e Sindromi aortiche acute: necessità di uno studio multicentrico}

\author{
Eduardo Bossone1, Santi Trimarchi2, Gloria Esposito4, Stefano Aliberti1, \\ Rodolfo Citro3, Luigi Allegra1, Francesco Blasi ${ }^{1}$
}

\begin{abstract}
Chlamydia Pneumoniae and Acute Aortic Syndrome: A Call for a Multi-Institutional Study. E. Bossone, S. Trimarchi, G. Esposito, S. Aliberti, R. Citro, L. Allegra, F. Blasi.

Chlamydia Pneumoniae (CP) infection is strongly associated with coronary artery disease, as well as with atherosclerosis of the carotid and peripheral arteries. However, the role of $\mathrm{CP}$ in the pathogenesis of aortic disease re-
\end{abstract}

\begin{abstract}
mains controversial. Our present experience suggests no correlation between a current infection with $C$. pneumoni$a e$ and acute aortic dissection. Well-designed large prospective studies are needed in order to clarify the pathophysiologic role of $\mathrm{CP}$ infection in acute and chronic aortic disease.
\end{abstract}

Monaldi Arch Chest Dis 2008; 70: 68-70.

\footnotetext{
1 Institute of Respiratory Disease, University of Milan, IRCCS Fondazione Policlinico-Mangiagalli-Regina Elena, Milano, Italy

2 Division of Vascular Surgery Istituto Policlinico San Donato, IRCCS, San Donato Milanese, Milan, Italy

3 Cardiovascular Department San Luca Hospital, Vallo della Lucania, Salerno, Italy

4 Chair of Vascular Surgery, Department of Thoracic and Cardiovascular Surgery, Scientific Institute H. San Raffaele, Vita-Salute University School of Medicine, Milan, Italy
}

Corresponding author: Prof. Eduardo Bossone, MD, Ph.D, FCCP, FESC, FACC; Dipartimento Cardiorespiratorio; Università degli Studi di Milano; Padiglione Sacco; Ospedale Maggiore Milano; IRCCS Fondazione Policlinico-Mangiagalli-Regina Elena; Via F. Sforza 35; I-20122 Milan, Italy; E-mail address: ebossone@hotmail.com

\section{Introduction}

The association between Chlamydia pneumoniae infection and cardiovascular diseases has been widely investigated in the literature [1]. C. pneumoniae has been proven to infect macrophages, endothelial and smooth muscle cells in arteries and particularly to be involved in aortic diseases [2-3]. However, the role of $C$. pneumoniae in development and progression of acute aortic dissection (AAD) remains controversial. We report the incidence of $C$. pneumoniae infection in a case series of patients affected by AAD.

\section{Clinical Summary}

Twenty consecutive patients with a AAD (Type A $\mathrm{AAA}=12$; Type $\mathrm{B} \mathrm{AAD}=8$ ) were prospectively enrolled in the study. AAD was diagnosed by imaging studies and/or during surgery. Data including demographics, past medical history, clinical presentation and physical findings on admission, imaging studies, details regarding medical and surgical management, and clinical outcomes were collected for each patient.

\section{Specimen collection}

Aortic specimens were collected in the operating room under sterile conditions. Arterial segments of approximately $4-5 \mathrm{~cm}^{2}$ were placed in tubes containing physiological solution. Transport vials were sealed in the operating room and subsequently opened in laminar air flow safety cabinets at the microbiology laboratory.

All the specimens were kept at $-70{ }^{\circ} \mathrm{C}$ until processing. Each aortic artery was subsequently cut transversely into smaller sections of $5 \mathrm{~mm}$ that were pooled and assayed by specific nested polymerase chain reaction (PCR). Chromosomal DNA was extracted by a commercial kit (Roche diagnostics, Germany).

\section{PCR amplification}

To confirm extraction, each DNA sample was tested for its ability to be amplified with B-globin specific primers. Primers amplifying 207-bp fragment of the major outer membrane protein genes (ompA) were used to detect $C$. pneumoniae by nested PCR. After amplification, a 4\% agarose gel electrophoresis and ethium bromide staining were used to visualize PCR products.

\section{Serology}

At the time of diagnosis a blood sample $(8 \mathrm{~mL})$ was collected for each patient in vacutaneir for isolation of peripheral blood mononuclear cells (PBMC) and serum. 
Serum antibodies (IgG, $\operatorname{Ig} \mathrm{A}, \operatorname{Ig} \mathrm{M})$ to $C$. pneumoniae were searched by a ANI Labsystems microimmunofluorescence (MIF) test. Serum samples were considered positive for titers $\geq 1: 64$ for IgG antibodies and $\geq 1: 16$ for $\operatorname{Ig} \mathrm{A}$ and $\operatorname{IgM}$.

\section{Results}

Demographics, past medical history, clinical, electrocardiographic and radiological findings, management and clinical outcomes of the study population are summarized in Table 1. C. pneumoniae $\operatorname{IgG}$ and $\operatorname{IgA}$ antibodies were detected in 14 (6 TA$\mathrm{AAD} / 8 \mathrm{~TB} \mathrm{AAD}$ ) out of 20 $(70 \%)$ and in 15 (7 TA $\mathrm{AAD} / 8 \mathrm{~TB} \mathrm{AAD}$ ) out of 20 $(75 \%)$ of patients, respectively. C. pneumoniae IgM were not detected in any patient. Only one TB AAD patient was PBMC PCR positive. $C$. pneumoniae DNA was not detectable in any of TA AAD tissue samples.

\section{Discussion}

Acute aortic syndrome (AAS), namely classic aortic dissection, intramural hematoma and aortic ulcer, is a highly lethal entity secondary to several genetic and acquired conditions. Complex mechanisms weakening the aortic media layers lead to higher wall stress eventually resulting in the clinical manifestations of the AAS [2].

Our present experience suggests no correlation between a current infection with $C$. pneumoniae and AAD. These findings support previous data: in the two small reports by Sodeck $\mathrm{G} e t$ $a l$. and Nyström-Rosander C et al., no signs of $C$. pneumoniae infections were detected in patients with TA-AAD [3-5]. However, two third of the patients presented a serologic evidence of previous $C$. pneumoniae infection.

Thus, the pathophysiological role of a potential concomitant C. pneumoniae infection in AAD remains not yet fully explored. Because of this and in light of the small number of patients studied, a need arises for well-designed large prospective studies in order (a) to further clarify the molecular mechanisms that link $C$. pneumoniae to the full spectrum

Demographics

Age (yrs)

Age $>70 y r s$

Clinical history

Hypertension

Migrating pain

Syncope

Chest x-ray

Normal

Pleural effusion

Electrocardiogram

Normal

Aortography
Table 1. - Demographics, clinical history and presentation, diagnosis, management and outcomes of the study population.

\begin{tabular}{lccc}
\hline Variable & $\begin{array}{l}\text { Type A AAD } \\
\text { n=12 }(60 \%)\end{array}$ & $\begin{array}{c}\text { Type B AAD } \\
\mathbf{n}=\mathbf{8}(40 \%)\end{array}$ & $\begin{array}{c}\text { Overall } \\
\mathbf{n}=20(100 \%)\end{array}$ \\
\hline
\end{tabular}

$59 \pm 11$

$62 \pm 11$

Marfan's syndrome

Bicuspid aortic valve

$64 \pm 11$

$\begin{array}{lll}7(58 \%) & 1(12 \%) & 8(40 \%) \\ 6(50 \%) & 4(50 \%) & 10(50 \%)\end{array}$

$\begin{array}{lll}7(58 \%) & 1(12 \%) & 8(40 \%) \\ 6(50 \%) & 4(50 \%) & 10(50 \%)\end{array}$

Previous aortic dissection

$1(8 \%)$

$10(83 \%)$

0

$1(5 \%)$

$5(42 \%)$

$5(62 \%)$

$15(75 \%)$

$1(8 \%)$

$1(8 \%)$

$3(25 \%)$

$1(8 \%)$

$4(50 \%)$

$9(45 \%)$

$1(12 \%) \quad 2(10 \%)$

$1(12 \%) \quad 2(10 \%)$

$0 \quad 3(15 \%)$

Previous cardiac surgery

$2(25 \%)$

$3(15 \%)$

Abrupt onset of chest pain

Any focal neurologic deficits

$11(92 \%)$

0

$4(33 \%)$

$3(25 \%)$

$5(42 \%)$

$3(25 \%)$

$8(100 \%)$

$19(97 \%)$

$2(25 \%) \quad 2(7 \%)$

$0 \quad 4(13 \%)$

$0 \quad 3(10 \%)$

$0 \quad 5(17 \%)$

$1(8 \%)$

$1(8 \%)$

$4(50 \%)$

$7(23 \%)$

Diagnostic imaging

Transesophageal echocardiography

Computed tomography

$2(15 \%)$

$3(10 \%)$

$1(12 \%)-2(7 \%)$

$2(25 \%) \quad 13(43 \%)$

Diagnostic imaging findings

$6(75 \%) \quad 10(33 \%)$

$4(33 \%)$

$2(17 \%)$

0

$2(7 \%)$

$7(58 \%)$

$3(37 \%)$

$10(33 \%)$

$8(40 \%) \quad 8(100 \%) \quad 16(53 \%)$

$2(17 \%) \quad 2(25 \%) \quad 4(13 \%)$

Periaortic hematoma

$5(42 \%)$

$1(12 \%)$

False luminal thrombosis

$3(37 \%)$

$6(20 \%)$

$3(25 \%)$

$5(42 \%)$

$5(42 \%)$

$3(37 \%)$

$6(20 \%)$

Aortic regurgitation

0

$8(27 \%)$

$1(8 \%)$

$5(17 \%)$

$1(3 \%)$

Definitive management
Surgical

In-hospital complications and outcome

Any focal neurologic deficits

Coma/altered consciousness

Myocardial ischemia

Acute renal failure

Limb ischemia

Mortality
$12(100 \%)$$$
0
$$

$6(50 \%)$

$4(33 \%)$

$3(25 \%)$

$1(8 \%)$

$3(25 \%)$

0

$2(17 \%)$
$12(80 \%)$

$8(40 \%)$

$7(35 \%)$

$4(20 \%)$

$3(15 \%)$

$1(5 \%)$

$\begin{array}{cc}2(25 \%) & 5(25 \%) \\ 1(12 \%) & 1(5 \%)\end{array}$

$0 \quad 2(10 \%)$

of acute and chronic aortic disease, (b) to fully investigate the clinical impact of $C$. pneumoniae infection in the development of AAS and (c) whether medical treatment may have a place in the prevention of this major life-threatening condition $[1,5]$.

\section{Riassunto}

L'infezione da Clamydia Pneumoniae (CP) è associata alla aterosclerosi coronarica, carotidea e pe- 
riferica. Peraltro, il ruolo della CP nella patogenesi della patologia aortica rimane controverso. La nostra presente esperienza suggerisce l'assenza di correlazione tra una infezione corrente da $\mathrm{CP}$ e la dissezione aortica acuta. Ampi studi prospettici sono necessari per chiarire un eventuale ruolo fisiopatologico della CP nelle patologie aortiche acute e croniche.

\section{References}

1. Mussa FF, Chai H, Wang X, Yao Q, Lumsden AB, Chen C. Chlamydia pneumoniae and vascular disease: an update. J Vasc Surg. 2006; 43: 1301-7.
2. Tsai TT, Nienaber CA, Eagle KA. Acute aortic syndromes. Circulation 2005; 112: 3802-3813.

3. Sodeck G, Domanovits H, Khanakah G, Schillinger M, Thalmann M, Bayegan K, et al. The role of Chlamydia pneumoniae in human aortic disease-a hypothesis revisited. Eur J Vasc Endovasc Surg. 2004; 28: 547-52.

4. Nyström-Rosander C, Hjelm E, Lukinius A, Friman G, Eriksson L, Thelin S. Chlamydia pneumoniae in patients undergoing surgery for thoracic aortic disease. Scand Cardiovasc J. 2002; 36: 329-35.

5. Lacro RV, Dietz HC, Wruck LM, et al. Rationale and design of a randomized clinical trial of beta-blocker therapy (atenolol) versus angiotensin II receptor blocker therapy (losartan) in individuals with Marfan syndrome. Am Heart J. 2007; 154: 624-31. 